\title{
Una sacra aventura en tierras que se volvían santas: Diego de Ocaña, O.S.H., 1599-1608
}

\author{
KenNeTH MiLLs
}

\section{RESUMEN}

En el presente ensayo, profundizo en las principales fuentes que sirvieron de inspiración a la relación manuscrita, ilustrada y sin título escrita por Diego de Ocaña, un recolector de limosnas ofrecidas a la advocación milagrosa de Nuestra Señora de Guadalupe de Extremadura, en la comarca de las Villuercas (España). El manuscrito es ahora conocido como Relación del viaje de fray Diego de Ocaña por el Nuevo Mundo (1599-1608). Sea porque tuvo una difusión limitada y permaneció inédito por largo tiempo, o porque se ha considerado de forma fragmentaria o de forma marginal respecto del canon de crónicas por la razón que sea, lo cierto es que su estudio en conjunto sigue en pañales. Se sabe bien que Ocaña era letrado, y se había señalado correctamente que resultaba crucial para la interpretación

1 Agradezco a los editores de la revista Allpanchis por facilitar la traducción de este trabajo y al profesor Carlos Arrizabalaga por su cuidadoso trabajo en la revisión del original y de la versión final. 
de su manuscrito apreciar la familiaridad más que evidente que revelaba su escritura con respecto de las novelas de caballería, con obras como la Araucana de Ercilla y con cronistas como Alvar Núñez Cabeza de Vaca. Pero más allá de las citas directas (que son pocas, tanto en el caso de Ocaña como en otros autores contemporáneos), en general, se ha subestimado la amplia cultura letrada de Ocaña. Lo más extraño de todo, dada su vocación religiosa, es que se hayan ignorado sus influencias de orden más espiritual. En este ensayo indago que hay otra clase de textos que estuvieron a su alcance y eran lectura habitual de sus principales destinatarios, textos en los cuales resultan esenciales las ideas y los asuntos profundamente sacros y elevados. Y me pregunto qué tanto habían orientado y conectado esas lecturas la manera como Ocaña contempla, imagina y describe las tierras las gentes y las realidades americanas, especialmente aquellas que él y sus compañeros necesitaban que fueren sacras y admirables. Sugiero finalmente que una inspiración fundamental para que Diego de Ocaña se presentase a sí mismo como peregrino y cronista piadoso reside en algunas relaciones tardo medievales de peregrinaciones a Tierra Santa así como relatos de viajes piadosos de la temprana edad moderna, caracterizados todos ellos por la riqueza y refinamiento de una tradición discursiva que se recrea constantemente.

Palabras clave: Diego de Ocaña, Orden de San Jerónimo, Pedro de Escobar Cabeza de Vaca, Copacabana, Carabuco

\section{Abstract}

In the present essay, I delve into one of the fundamental inspirations behind an untitled, illustrated manuscript by Diego de Ocaña, an alms-collector travelling on behalf of the miraculous advocation of Our Lady of Guadalupe de Extremadura in the Villuercas mountains: the manuscript now known as the Relación del viaje de fray Diego de Ocaña por el Nuevo Mundo (15991608). Because the manuscript did not circulate widely and long remained unpublished, and because it has usually been fragmentarily employed if not marginalized from the chronicling canon for one reason or another, study of its whole remains in its infancy. It has long been known that Ocaña was a rea- 
der; and it has been correctly proposed that the appreciation of Ocaña's evident familiarity with certain romances de caballería, with Alonso de Ercilla's La Araucana and with cronistas such as Alvár Núñez Cabeza de Vaca would be crucial to interpreting his manuscript. But, beyond direct citations (which are few, both in Ocaña's case and by other contemporary authors), the broader readerliness of Diego de Ocaña has been underestimated. Most oddly of all given his religious vocation, his more spiritual influences have been neglected. I ask in this essay what other kinds of texts in which matters and things deemed sacred and notable were central, were available to him and expected by his principal readers. I ask how such readings may have focussed and enabled Ocaña's ways of seeing, imagining and portraying American lands, people, and phenomena, especially those which he and others needed to be sacred and notable. I suggest that a fundamental inspiration for Diego de Ocaña's presentation of himself as a sacred adventurer and reporter lay in the richly honed, and thus highly re-generative, repertoires offered by late medieval and early modern accounts of pilgrimages to the Holy Land and related sacred journeys.

Keywords: Diego de Ocaña, Order of Saint Jerome, Pedro de Escobar Cabeza de Vaca, Copacabana, Carabuco

CON SU ESPLENDOR ARQUITECTÓNICO, sus torres y capiteles, no hay templo en España que sea su igual, ni iglesia más famosa, ni templo «con mas perfeccion acabado» -insistía Gabriel de Talavera en 1597- que el ilustre santuario de la imagen milagrosa de Nuestra Señora de Guadalupe, en Extremadura. Para quien fuera dos veces prior de la comunidad jerónima guadalupana, el esplendor material reflejaba correctamente la grandeza espiritual, convocando «la justa admiración del mundo» (Talavera 1597: 31v). Se entendía que las estructuras materiales inspiraban devoción tanto como admiración. El santuario guadalupano era «casa de Dios y puerta del cielo», y también «mina» que abundaba en tesoros preciosos o «fuente» que 
apagaba toda clase de sed (Talavera 1597: 422r). La recompensa «que paga Nuestra Señora» alcanzaba a todo aquel que tuviera la fortuna de estar en el lugar, pero más especialmente a aquellos viajeros piadosos que afrontaban «el trabajo de los caminos y peregrinaciones» para llegar hasta allí (Talavera 1597: 420v).

Dios había previsto conceder a los cristianos una abundancia de lugares santos. Y las noticias acerca de su divina magnificencia llegaban así a todas partes. Al escribir ya finalizando un siglo que había sido testigo de un número asombroso de «historias de santuarios y colecciones de testimonios milagrosos» -las imprentas los difundían sin descanso por todos los reinos españoles peninsulares (Christian Jr. 1981: 103) - y en una época de agudas dificultades económicas para los religiosos jerónimos en Guadalupe, Talavera buscó hacer hincapié en la especial importancia de la santa casa guadalupana. En los estantes de una librería monástica que debió haber conocido tan bien como cualquier otro monje jerónimo de su tiempo, Talavera halló un relato publicado hacía muy poco acerca de una peregrinación a Tierra Santa, dividido en veinticinco cantos escritos en verso libre por un soldado en retiro originario de Valladolid.

Pedro de Escobar Cabeza de Vaca había zarpado de Messina, Italia, el 12 de septiembre de 1584, y a lo largo del otoño y del invierno subsiguientes llevó a cabo un extraordinario recorrido por Egipto y Tierra Santa, que incluyó provechosas estancias en Alejandría, El Cairo, Jerusalén y otros sitios sagrados de Palestina, así como el Monte Sinaí. Su Luzero de la Santa Tierra apareció por primera vez en 1587 y a esta edición le siguió una en 1594 (Escobar Cabeza de Vaca 1587). ${ }^{2}$ Se trataba de uno entre una verdadera inundación de libros y tratados de la misma clase que aparecieron para los lectores del Medioevo tardío y los tempranos tiempos modernos, hambrientos de narraciones de viajes e información sobre el

2 He revisado la edición original del Luzero de la tierra santa en la colección de la Boston Public Library, George Ticknor Bequest: D.270b.20. 
paisaje sagrado del Oriente cristiano (Beaver 2013: 56-57; Lama de la Cruz 2015: 368-372). Si bien muchos de estos relatos procedían de viajeros piadosos o peregrinos originarios de la Península Ibérica, incluyendo (como veremos) a frailes jerónimos de Guadalupe, ${ }^{3}$ también hubo una buena cantidad de relatos provenientes de otros lugares, en especial de tierras germanas, que habían alcanzado una fama creciente. ${ }^{4}$

3 Fray Antonio de Lisboa, Viaje a Oriente (1507), y Fray Diego de Mérida, Viaje a Oriente (1512), fueron monjes jerónimos. Entre los demás peregrinos españoles y portugueses estaban Guillén Ollivier (ca. 1464); Fadrique Enríquez de Ribera (ca. 1519; ediciones de 1521, 1606, 1608 [1974]); Antonio de Aranda (publicado en 1537); Pedro Ordoñez Ceballos (ca. 1565-1602; [1993]); Pantaleão de Aveiro (ca. 1566; primera edición de 1583, [1927]); el antes mencionado Pedro de Escobar Cabeza de Vaca (publicado en 1587); Francisco Guerrero (publicado en 1592 [1984]); y Juan Cerverio de Vera (ca. 1595, publicado en 1596 [1964]), a quien trataremos más adelante. Acerca del alcance de los relatos de viajes de peregrinación a Tierra Santa en los siglos XVI y XVII, véase el estudio introductorio y ediciones selectas de Joseph R. Jones, que incluyen una trascripción del Luzero de Escobar de Cabeza de Vaca (Jones, ed., 1998), y también los estudios de Lama de la Cruz (2015) y Tena Tena (1990), todos los cuales se basan sobre los estudios pioneros acerca de relaciones de peregrinaciones medievales de Lasso de la Vega (1882).

4 Acerca de lo que aparecía en los principales centros de impresión en Alemania, como Frankfurt, Nuremberg y Mainz, véase Weiss (1988). Basta aquí con decir que el libro más difundido fue el Peregrinatio in Terram Sanctam de Bernard von Breydenbach (d. 1497), con sus excelentes (y varias veces reproducidos) grabados, hechos por Erhard Reuwich de Utrecht, publicado originalmente en latín en Mainz, en 1486, y que vio doce ediciones en 1522, así como prontas traducciones al alemán, neerlandés, francés y español. Este último apareció en Zaragoza (1498) en una traducción de Martín Martínez de Ampiés, quien además añadió una parte acerca de Roma dedicada a los peregrinos que buscaban autorización para hacer el viaje, y otros detalles y comentarios al texto original. Una edición moderna es el Viaje de Breidenbach (1974). Fueron también notables, Félix Fabri, Evagatorium in terrae sanctae (1494); los diecisiete relatos alemanes de entre 1495 and 1573, junto con Mandeville, en el Reyszbuch dess Heyligen Lands, una antología compilada por el impresor de Frankfurt Sigmund Feyrabend; y el famoso Book of Marvels de Sir John Mandeville, traducido al español en 1540 (Valencia) y en 1547 (Alcalá de Henares), etc. 
Este ensayo no es lugar para un examen completo de la biblioteca monástica de Guadalupe de Extremadura, ni tampoco del conjunto de materiales y prácticas de lectura que realizaban los frailes jerónimos a fines del siglo XVI. Para nuestro propósito será suficiente decir que en el convento guadalupano un certificado de buena conducta hubiera bastado para que un novicio o fraile accediese libremente a los inacabables anaqueles de una de las mejores y más nutridas bibliotecas de toda España. ${ }^{5}$ «Finalmente, concluye Talavera, de todo quanto ay escrito es copiosa la multitud que este edificio encierra» (Talavera 1597: Libro IV, 202). Las minuciosas indagaciones de Hermenegildo Zamora sugieren que al menos en lo que respecta a las colecciones de la tradición judeo-cristiana y de la cultura occidental, la devota hipérbole de Talavera no estaba tan lejos de la verdad. En el tardío siglo XVI y los inicios del XVII, los lectores conventuales del monasterio de Guadalupe podrían acceder no solo a copias de manuscritos sino a una verdadera explosión de textos impresos en lengua vernacular con gran variedad de géneros -a menudo superpuestos- tanto espirituales como profanos (Chevalier 1976; Bouza Álvarez 2001). Respecto a los temas espirituales, los reglamentos vigentes en la orden de San Jerónimo nos permiten vislumbrar varias clases de lecturas, entre las que había muchas oportunidades de escuchar textos; así también las medidas que se contemplaban en la reforma de algunas de sus casas, así como las descripciones contemporáneas de cómo los jerónimos preparaban a sus novicios se muestra cómo establecían un variado régimen de lecturas en la vida monástica.

5 La construcción de una biblioteca guadalupana más espaciosa, y decorada con hermosos murales al fresco, comenzó a mediados del siglo XV, para albergar no solo su amplia colección de manuscritos sino más aún para dar cabida a una muy importante y creciente colección de libros impresos. Ver Libro de la invención (Ecija [ca. 1514] 1953: 296); Historia de Nuestra Señora (Rubio 1927: 274, 108); Catálogo de libros de la antigua biblioteca (Zamora 1976: v). 
Aquí como en otras materias, José de Sigüenza (1544-1606), un renombrado jerónimo contemporáneo que combinaba con elocuencia sus investigaciones sobre la historia de la orden y los ideales de la regla con los recuerdos de su propio noviciado - «en la casa [de Santa María] del Parral de Segovia (...) donde me crie, y a quien devo agradecimiento perpetuo»- emerge (Sigüenza 2000: Tomo 1, (Sigüenza 2000: Tomo 1, Libro 2, Ch. 21, 336, col. 2). ${ }^{6}$ Sigüenza explica que los frailes eran advertidos de la importancia del estudio en privado de textos espirituales que primero habían puesto en común (en el refectorio y en otros momentos de meditación en el coro): la Escritura y las historias bíblicas, sobre todo los hechos de los apóstoles y mayormente las epístolas de san Pablo; las enseñanzas de los padres de la Iglesia (entre los que destacan los escritos de Juan Casiano); selecciones de vidas de santos, con especial atención la vida de san Antonio en el desierto de Egipto, escrita por Atanasio y las relaciones de la vida contemplativa y letrada de san Jerónimo, patrón de la orden.

Me gustaría enfatizar, primero, que el tesoro oculto de esos textos espirituales expresados para animar la imaginación devota, se veía complementado por otras varias clases de textos, en concreto relaciones de peregrinaciones a Oriente y otros relatos de viajes, sacros o de otra clase. Por ejemplo, además del Luz̧ero de Escobar Cabeza de Vaca, el texto con el que comencé mi ensayo, los jerónimos de Guadalupe también profundizaban en la famosa relación de Antonio del Castillo y su peregrinación a Tierra Santa. Y podrían explorar todavía más allá, consultando la Suma de Geographia de Martín de Enciso Fernández, la Relación y Comentarios de Alvar Núñez Cabeza de Vaca (conocida como los Naufragios) y los hechos

6 Sigüenza compuso una Instrucción hacia 1580 para orientar a los jerónimos formadores de los novicios, que circulaba para uso interno, a la vez que dedicaba diez capítulos al tema dentro de su ya mencionada historia de la orden jeromítica (1595-1605). La Instrucción, como libro exento, circuló manuscrito entre los jerónimos pero no fue publicado hasta 1712 y nuevamente en 1793 (Sigüenza 1793). 
ocurridos en el Nuevo Mundo, y todo un conjunto de novelas de caballería. En su debido momento (entre sus publicaciones), las ficciones de aventuras también habrían formado parte de la biblioteca, incluyendo Mateo Alemán y la Primer y Segunda partes de Guzmán de Alfarache y Miguel de Cervantes, con el Quijote (por mencionar algunos). Más aún, en el primero y más antiguo catálogo que se conserva de la biblioteca de Guadalupe, junto al nombre dado de un fraile se indicaba la palabra dormitorio, y esto ocurre unas 304 veces a lo largo de los márgenes de los títulos de muy diferentes títulos; este hecho sugiere nítidamente que una variedad de libros circulaba muy probablemente en calidad de préstamo por los frailes que tenían permiso de leer en sus celdas privadas y en el dormitorio de novicios descrito igualmente por Talavera (Zamora 1976: 92, 3, 77, 149, 14, 10, xv-xvi).

También quiero señalar, en segundo lugar, que la evidencia que voy a explorar a continuación respecto de un fraile jerónimo (Diego de Ocaña, acerca de cuyo viaje a lo largo de las Indias estoy preparando un libro más extenso), indica que estos frailes modernos, al leer los textos y reportar toda clase de cosas desde «los ojos de la fe», no separaron géneros ni categorías en su inspiración letrada, del modo como lo suelen hacer los autores del siglo XX (Hunt 2000: 39; 1982: 185-188; Weber 2005). En fin, aprender de la Escritura, de las vidas de santos y de noticias de milagros no era algo marcadamente diferente de otras oportunidades de contemplar las acciones humanas y los designios de Dios en la literatura pastoral o en novelas de caballería, obras picarescas, poemas épicos de carácter histórico, racimos de obras dramáticas, historias de órdenes religiosas y de imágenes sagradas, cartas, reportes y crónicas de los nuevos mundos al otro lado del océano y por último, para lo que respecta a nuestro estudio, relatos de viajes a Tierra Santa y su entorno.

Así Talavera, junto con hermanos menos conocidos, seguramente admiraba muchas cosas del Luzero de la Santa Tierra y de otros relatos de viajes sagrados. Con respecto al Luzero sabemos, sin em- 
bargo, que apreciaba particularmente la manera como al describir los Santos Lugares de la fe cristiana, aquel poeta-peregrino aludía también a sitios sagrados que eran familiares para los lectores españoles, entre ellos, por supuesto, el santuario jerónimo de Guadalupe. En uno de los puntos más importantes de su recorrido, Escobar Cabeza de Vaca se halla delante del «muy solemne y rico Monasterio», el mismo que se decía había sido edificado por santa Elena (ca. 250-330 d.C.), madre del Emperador romano Constantino. Talavera se entusiasmaba de que «el auctor del Luzero de la tierra santa», queriendo evocar el poderío inspirador de aquellas edificaciones de santa Elena, hubiera afirmado que con nada se las comparaba mejor que con el santuario de «Sancta María de Guadalupe», en Extremadura (Talavera 1597: 31; Escobar Cabeza de Vaca 1587: f. 154v). ${ }^{7}$ Aquel poeta-soldado en peregrinación había recordado el famoso santuario de Guadalupe. A su turno, un contemporáneo suyo, un historiador eclesiástico de la Orden de San Jerónimo, había adoptado aquella comparación de su amada casa con un famoso y reverenciado lugar de la Tierra Santa. ¿Qué es lo que estaba sucediendo? Propongo que esta forma aparentemente automática de vinculación entre lugares y tiempos alejados, hecha por dos cristianos españoles de fines del siglo XVI, manifestaba algo que no resulta aparente a primera vista.

Para empezar, la comparación de los edificios del santuario de Guadalupe con el esplendor de la sagrada fundación de santa Elena en Belén no era poca cosa. Se trata de un testimonio del acendrado renombre de ambos lugares en la mente española de fines del siglo XVI. Pero, de manera más precisa, pone de manifiesto cómo funcionaban los esquemas mentales universalistas e imperativos de Escobar Cabeza de Vaca y de Talavera. Su inclinación a establecer

7 Antes, en el Luzero, Escobar Cabeza de Vaca hace algo parecido al comparar la iglesia del Santo Sepulcro en Jerusalén con «la real iglesia de Toledo»: (Luzero, Canto XIII, f. 101r-101v). 
aquellas comparaciones se corresponde perfectamente con la entusiasta exhumación y traslado de huesos, sangre y cenizas de cuerpos de santos a santuarios y altares de lugares alejados, o al movimiento de otra clase -menos dramática- de objetos de Tierra Santa, prácticas todas estas muy bien documentadas a lo largo del Mediterráneo y la Europa de la Antigüedad tardía, el Medioevo y la temprana Era Moderna (Geary 1978; Klein 2010). Dado que, manifiestamente, no todos los lugares habían sido bendecidos con la presencia física de Cristo como el Monte Calvario o la tumba de la Resurrección, y que no todos los sitios podían jactarse de vestigios materiales de mártires y santos como Jerusalén o Roma, los creyentes -en tándem con los historiadores eclesiásticos-aspiraban a establecer conexiones en distintas formas complementarias.

Para personas como Escobar Cabeza de Vaca y Talavera, la posibilidad de escribir y de leerse mutuamente -así como de leer otros muchos relatos de peregrinación a Tierra Santa e historias de santuarios- equivalía a un acto de reconocimiento a través y por entre la experiencia, el espacio y los distintos fenómenos bíblicos, históricos y contemporáneos. Veían todo con «ojos de fe» y se hizo natural, en la medida de que era necesario, contemplar no solo Tierra Santa y los reinos peninsulares de España, sino también los «nuevos mundos» de las Indias Occidentales y Orientales, y verlos como partes interconectadas de un paisaje sagrado que se iba desenvolviendo a través del tiempo. Había modos precisos para atravesar y conectar puntos exquisitos dentro de este paisaje que podían aprenderse y perfeccionarse. Las medidas concretas adoptadas por los padres de la Iglesia en el Concilio de Trento (1545-1563), respecto de la autenticidad de las reliquias y del uso devoto de las imágenes y su veneración apropiada y respetuosa y en torno a los milagros atribuidos a la intercesión, frenaron un poco pero nunca restringieron la entusiasta devoción popular. ${ }^{8}$ Como ha remarcado William B. Taylor, las for-

8 Ver especialmente los decretos de la vigésimo quinta sesión los días 3 y 4 de diciembre de 1563 (Tanner, ed. 1990, 2: 774-776). Trento es importante pero la 
mas habituales de comprensión de la presencia divina y de cómo podía manifestarse en las cosas materiales, y especialmente en las «reliquias óseas y objetos que habían pertenecido a héroes cristianos», no se circunscribían al área del Mediterráneo y a Europa; estas formas de comprensión mostraban una gran capacidad de adaptarse y relocalizarse en escenarios del Nuevo Mundo (Taylor 2016: esp. cap. 6). Surgen por todas partes nuevas rutas de peregrinación que a veces llegaban a cubrir grandes distancias, una de las más famosas en las tierras españolas fue la red de rutas de peregrinación que conducen a la tumba de Santiago el Mayor en Santiago de Compostela. Abundan los ejemplos de inmediatez y realismo en la recreación de los lugares santos en estos nuevos territorios sagrados, en sitios específicamente periféricos a los que se atribuía un fuerte significado espiritual (Weber 2005; Taylor 2016: cap. 9). Lo que interesaba era establecer las distancias que las personas podían cubrir y las vinculaciones que podían establecer en sus mentes.

Respecto a la emperatriz Elena, digamos también que un puñado de historias compuestas poco después del Concilio de Nicea había referido prolijamente su peregrinaje por las sagradas provincias orientales romanas entre el 326 y 328 d.C. En la parte más importante de estos relatos se hallaba su búsqueda -ardua aunque finalmente exitosa- de la Vera Cruz, y de los clavos que habían atravesado al Salvador. Pero la determinación de Elena dio además otros frutos tangibles.

En su panegírica Vida de Constantino, escrita en griego e inconclusa al momento de su muerte, Eusebio de Cesarea (ca. 260-

intención y los efectos de sus decretos deben ser entendidos como una parte de un proceso prolongado de reforma de las devociones. Como señaló en su trabajo pionero William A. Christian Jr. (1981), para el caso peninsular, las normas tridentinas, aunque estrictas, pueden ser vistas como prolongación de prácticas habituales: «the continuation of the practice of many of the shrines in Spain as early as the mid-fifteenth century» [«la continuación de lo practicado en la mayoría de los santuarios españoles en fechas tan tempranas como desde mediados del siglo XV». Traducción del editor] (Christian 1981: 102-105). 
340 d.C.), contemporáneo de esa famosa peregrinación, había dedicado abundante atención a los píos proyectos que la visión y la munificencia de Elena habían propiciado. «Hemos de venerar el lugar que Sus pies han hollado», proclama la Elena de Eusebio, unas palabras proféticas que serían acicate para que generaciones de peregrinos caminaran hacia los lugares que ella se esforzó en edificar. Pronto dos templos se levantaron en Belén, «uno en la gruta que fue el lugar donde nació el Salvador», explica Eusebio, «y el otro en el monte de su Ascensión». Respecto de la obra que ella comenzara en la sagrada gruta, Constantino solo añadió «a la largueza de su madre costosos presentes de plata y oro, así como tapices bordados». En beneficio de «la majestuosa construcción en el Monte de los Olivos», que Elena había levantado para conmemorar las secretas comunicaciones del Salvador con sus discípulos y su Ascensión a los cielos, también el Emperador contribuyó con «regalos aún más variados y costosos» (Eusebius 1890, Libro 3, caps. 42 y 43; Eusebius 1999). ${ }^{9}$

Pocos de los hagiógrafos que siguieron la estela de Eusebio de Cesarea dejaron de entusiasmarse con los relatos en torno al peregrinaje de santa Elena, madre de Constantino, por los Santos Lugares. Lo central era aquí el interés por lo que aquel autor calificara como «sus nobles y hermosos monumentos de devoción, dignos de eterna memoria, dedicados a la gloria de Dios, su Salvador, y pruebas de su santo celo» (Eusebius 1890, Libro 3, cap. 43). Elena, la promotora de fundaciones santas en lugares sagrados de Belén, la edificadora de importantes y admirables edificaciones en Jerusalén, resonó en la mente de los lectores y atrajo a peregrinos e intelectuales durante siglos. Si bien el tratamiento que hace Santiago de la Vorágine acerca de Elena, en su Leyenda Aurea de mediados del siglo XIII -una de las vidas de santos más veces reimpresa en

9 Para un escéptico de las aseveraciones de Eusebio y estudioso de las motivaciones detrás del monolítico elogio de Elena y Constantino, véase Barnes (1981). 
Europa entre 1470 y 1530-, tuvo mucha influencia, el freno que a las exageraciones legendarias y renovaciones similares se produjo durante las sucesivas impresiones del Flos Sanctorum, durante y después del Concilio de Trento (1545-1563), sirvió asimismo para adaptar y hacer asequible la Emperatriz a un más amplio espectro de lectores españoles. ${ }^{10}$ Dado que Escobar Cabeza de Vaca y Gabriel de Talavera se interesaron tanto en las fundaciones de santa Elena en Tierra Santa, no debe sorprendernos el que su contemporáneo, el jesuita Ribadeneyra, pusiera énfasis no solo en las famosas edificaciones de Belén sino que además le atribuyera a este personaje el esfuerzo de la erección de unas «treinta yglesias en Jerusalem y otras partes [...] adornándolas y proveyéndolas de todo lo necesario para el culto divino» (Ribadeneyra 1604: 178; 177-178).

El universalismo cristiano del imaginario español, que relacionaba a Tierra Santa con la España peninsular, buscó asimismo que estas vinculaciones incluyeran a las posesiones españolas de las Indias, occidentales y orientales. Las comparaciones y vinculaciones eran, a veces, explícitas, como en los casos de Pedro de Escobar Cabeza de Vaca y Gabriel de Talavera, a los que nos hemos referido más arriba y a los que regresaremos más adelante.

Pero había otros textos relacionados que también influyeron. Singularmente atractivo es, en este sentido, el caso de Juan Ceverio de Vera (1550-1600), nacido en las Islas Canarias y peregrino de Tierra Santa en 1595, luego de haber pasado a Indias, en un viaje que le haría conocer las extensiones americanas. En el curso de su relato, Ceverio de Vera integra descripciones de gentes, lugares y cosas de América, y establece asociaciones inmediatas entre las muchas dificultades que enfrentó en las Indias, con los encuentros, experiencias y obstáculos que vivió a través de Tierra Santa. Su lógica asociativa y

10 Especialmente la del jerónimo Pedro de la Vega (Vega 1588), el hagiógrafo lego Alonso de Villegas y Selvago (Villegas y Selvago 1588) y, a su tiempo, el jesuita Pedro de Ribadeneyra (Ribadeneyra 1599-1601; 1604). 
su manera de establecer referencias entre elementos dispares, desde lugares santos notables, pasando por pueblos musulmanes e indígenas, hasta desastres naturales y las prácticas de los especialistas de otras religiones, son dignas de mención, pero al mismo tiempo se corresponden enteramente con lo que hemos considerado antes para los casos de Escobar Cabeza de Vaca y Gabriel de Talavera. Para el peregrino Ceverio de Vera todo peregrinaje sagrado es en realidad uno solo y una manifestación de lo que Martín de Braga (520-580) -que había también peregrinado, por su parte, a Tierra Santa- consideraba un «acto religioso en sí mismo» (Dietz 2015: 166). La exigente experiencia de recorrer esos «lugares desiertos», desde las más tempranas formulaciones eremíticas y monásticas, se había convertido en algo que era a la vez metafórico y literal en la imagen que, de ellos mismos, tenían los piadosos viajeros, y era probable que ello tuviera un efecto persuasivo en lectores informados que sintonizaban con el espíritu religioso de esos viajes (Constable 1988: 242-249; Dietz 2005: 73-78).

De acuerdo con un admirador contemporáneo (que escribió en 1652 acerca del final de la vida de Ceverio de Vera), este había atribuido su supervivencia a lo largo de sus muchas pruebas y caminos a un pequeño retrato de la Virgen María que llevaba a todas partes, una copia de la imagen que el mismo san Lucas habría pintado en vida. Luego de su estadía en la América española, y al poco de regresar de Jerusalén, buscó cumplir con su voto de dar a aquella importante reliquia un lugar de descanso, pero no sabía cuál. Se sabe que Ceverio de Vera había visitado los santuarios de Nuestra Señora del Pilar en Zaragoza, de la Virgen de Atocha en Madrid y de Nuestra Señora de Guadalupe en Extremadura, antes de que recibiera una señal. Se dice que las instrucciones para el peregrino vinieron de Gregorio Magno, en una visión, en la que se le indicó que buscara el santuario de Santa Brígida en Lisboa, donde, cumplidos los trabajos de su vida, murió (Cardoso 1652, 2: 649-650; Millares Carlo 1932: 170-176; Martínez Figueroa y Serra Rafols, en Ceverio de Vera [1596] 1964: xiii-xiv). 
Con más frecuencia, sin embargo, una lógica asociativa y un esquema mental universalista similares, así como la influencia de los relatos populares de peregrinaciones a Tierra Santa respecto de aquello que los empeñosos peregrinos deseaban hallar (y en efecto encontraban en las Indias), obraban conjuntamente de manera más sutil, más implícita. En otro lugar he explorado cuán profundamente grabada estaba en la mente de muchos clérigos españoles, durante los primeros años de la Era Moderna, la expectativa y la experiencia de hallar pruebas difíciles y duras en el mundo exterior, y de manera especial en aquellos que abrazaban misiones en ultramar. Las cartas de san Pablo, los Hechos de los Apóstoles, numerosos ejemplos de las Escrituras, las enseñanzas de los Santos Padres, apropiaciones de los clásicos grecolatinos, todo ello anunciaba las recompensas espirituales que provenían de los sufrimientos y privaciones de las comodidades mundanas. Pocos viajes, al parecer, ofrecían mejores oportunidades de experimentar el desierto que un traslado lleno de determinación a las Indias (Mills 2014: esp. 116-118).

Como resultado de ello, al describir los propios viajes americanos $-\mathrm{o}$ los que emprendieron otros- y a la gente, los lugares y las cosas, no pocos españoles de la temprana era moderna, y sus lectores, se dedicaron a elaborar lo que Scott Fitzgerald (refiriéndose a la Antigüedad tardía) ha descrito como una versión profundamente cristiana de «paráfrasis literaria», una práctica que tiene que ver, más bien, con el tipo de «intertextualidad» histórica que estudian eruditos literarios entre quienes destaca Linda Hutcheon, entre otros (Johnson 2006: 10, 6-10; Hutcheon 1988; (Bakhtin 1981: 88); Kabatek 2008, 2007; Oesterreicher 2004). El tema central que debemos considerar aquí es, en primer lugar, lo que Mikhail Bakhtin llamó la «conexión intrínseca» a través del tiempo y el espacio (Bakhtin 1981, 88). En resumen, todos los relatos, cualquiera sea su grado de originalidad, son fundamentalmente re-cuentos, y ciertos grupos se fertilizan y reinventan dentro de tradiciones dinámicas. Y, en segundo lugar, que los autores de estos re-cuentos frecuentemente no 
tienen consciencia de cuáles son sus influencias, modelos, patrones $y$, si se quiere, moldes. Para que un autor pudiera resonar en la actualidad de aquella temprana era moderna, ella o él hallaron medios para expresar eso que sus lectores necesitaban y esperaban.

Lo que el ejemplo académico de Sabine MacCormack demostró, de manera magistral, acerca de la influencia de los modelos e «historias» de los romanos clásicos respecto de la propia imagen de los españoles y el retrato que formularon de los incas, el Tahuantinsuyo y las distintas problemáticas del Perú temprano colonial, es lo que ahora yo trato de sostener respecto de los relatos de Tierra Santa y su vinculación con las descripciones de peregrinaciones religiosas en las Indias. Estas nuevas relaciones fueron posibles gracias a una serie de patrones narrativos, más antiguos, que ejercieron su influencia de maneras que van más allá de la apropiación directa, incluyendo juegos aún más sutiles respecto de la forma, y reinvenciones de las texturas, humores y códigos internalizados en los textos del pasado. No afirmo de ningún modo que los protagonistas-narradores de la temprana era moderna estuviesen inventando por completo sus experiencias y los fenómenos observados en las Indias; más bien, trato de hacer hincapié en la naturaleza heredada de ese modo interconectado que tenían ellos y sus lectores de comprender la realidad. Las realidades de estos autores, como las nuestras, consistían en buena parte en aquello que estos estaban condicionados a buscar y, por ende, a encontrar y que como escritores expresaban, reformulando sus experiencias en claves narrativas que les eran familiares; siguiendo formas narrativas como los relatos de peregrinaciones a Tierra Santa, muy apreciados en parte debido a que eran a la vez elásticos y estaban muy perfeccionados.

En su monasterio de Guadalupe, los acuciosos jerónimos del tardío medioevo y la temprana era moderna no fueron ajenos a los libros y manuscritos que circulaban, ni al impacto creciente de la imprenta en su tiempo. En lo que respecta a los relatos de peregrinaciones a Tierra Santa, algunos frailes no eran solo lectores, ya que 
emprendían y relataban sus propios viajes. Ejemplo claro de ello es una compilación de relaciones de fines del siglo XIV e inicios del siglo XV escritas por jerónimos y otros peregrinos, efectuada alrededor de 1520 por un compilador y comentarista anónimo de Guadalupe, con seguridad un fraile, que acababa de regresar de un viaje a Tierra Santa (Anónimo ca. 1520; en Jones, ed. 1998: 107-243). La «grandeza e sumptuosidad de torres e edificios» de las sacras edificaciones atribuidas a santa Elena en Belén -señala el autor en un punto- «era casi como el monasterio de Sancta María de Guadalupe» (Anónimo ca. 1520, f. 224r, en Jones, ed. 1998: 217). ${ }^{11}$ Esta reverente comparación anticipa tan claramente a aquella otra que fuera hecha casi tres cuartos de siglo más tarde por Escobar Cabeza de Vaca (y asumida por Talavera), que es imposible no imaginarse a este soldado-peregrino de Valladolid como uno de los lectores de aquella compilación.

En 1599, un contemporáneo castellano del soldado-peregrino Escobar Cabeza de Vaca y del prior e historiador jerónimo Gabriel de Talavera, un joven fraile de nombre Diego de Ocaña (ca. 15701608) partió a las Indias como demandador. Este encargo consistía en la recolección de limosna para la imagen milagrosa de Nuestra Señora de Guadalupe en Extremadura, específicamente para sustento de la multitud de peregrinos que acudía a Guadalupe cada año, y para el sostenimiento de un culto digno de la Madre de Dios. Como mensajero de la María guadalupana y como agente autorizado de su

11 Anónimo, Viaje de Tierra Santa [ca. 1520]. El texto se conserva en la Biblioteca Nacional de España, Ms. 10883, f. 2r. (Jones, ed. 1998: 110). El texto principal de esta compilación es una carta de varios capítulos, escrita por fray Diego de Mérida en 1512; otros pasajes provienen del relato de fray Antonio de Lisboa (1508), quien viajó con su hermano Pedro Martínez de Silva. Tanto Mérida como Lisboa fueron religiosos jerónimos profesos en el monasterio de Guadalupe en Extremadura. También se hallan compilados pasajes del relato de un franciscano, Antonio Cruzado (1483), y de otro relato de don Fadrique Enríquez de Ribera, Marqués de Tarifa, que visitó Guadalupe en octubre de 1520, con una relación de sus viajes a Tierra Santa (1518-1519). 
Orden, con un compañero más experimentado, Martín de Posada, Ocaña marchó de su sagrado centro con la idea de propagar la historia y el poder de aquella imagen y (cuando fuese necesario) reformar las comunidades de devotos en lugares alejados, constituyendo estructuras de sustento, de manera que el régimen de limosnas de las nuevas santas fundaciones durase para siempre (Mills 2008). Posada enfermó en el viaje a las Indias. Su salud se deterioró seriamente en el trayecto por el Caribe y en el paso del istmo del Darién a Panamá. Allí se dirigieron al sur a bordo de un velero de la flota de la Mar del Sur, la Galizabra, hasta desembarcar en el puerto de Paita el 2 de setiembre de 1599. Posada murió solo unos pocos días después, dejando solo a Ocaña, quien eventualmente describe este inesperado giro de los acontecimientos en la costa norte del Perú en un largo proceso de dar relación completa de sí mismo así como de su misión y viaje, los mismos que para él, en cierto modo, comenzaron en Paita. Mucho de lo que sabemos de Diego de Ocaña proviene de lo que él mismo escribió, dibujó y pintó en un manuscrito sin género definido, de unos 319 folios (algunos sin numerar), sin página de título y tal vez nunca tuvo título, pero que se conoce como Relación del viaje de Fray Diego de Ocaña por el Nuevo Mundo (Ocaña 1599-1608; Ocaña 2010). El manuscrito parece haberse elaborado gradualmente. No hay borradores, esquemas o cuadernos previos, pero la evidencia del texto mismo sugiere internamente que Ocaña hizo una copia final de varias porciones de su manuscrito en el que habría trabajado durante sus largas estadías vividas en las ciudades de Potosí, Chuquisaca (hoy Sucre) y, especialmente, en Lima. Hay también indicación de que estaba terminando al menos sus ilustraciones y tal vez algo más luego de su travesía a México, capital del virreinato de Nueva España, a inicios de 1606, y en los meses previos a la noticia de su muerte, ocurrida en Guadalupe el 17 de noviembre de $1608 .^{12}$

12 La Relación del viaje de Fray Diego de Ocaña por el Nuevo Mundo (1599-1605) es designada con la signatura M-215 en la Biblioteca de la Universidad de Oviedo, 
Ocaña tenía permiso real para llevar una buena cantidad de libros a las Indias. Ocasionalmente hace referencia a ellos, y en ninguna parte de forma más dramática que en el momento de atravesar el istmo de Panamá, donde atribuye a la especial protección de la Virgen el que los libros no se hubiesen dañado en el agua, como si se hubiese tratado de un milagro. Su biblioteca itinerante era transportada en cofres y su tamaño requería de los lomos de cinco mulas (Ocaña 2010: f. 14v-15r, 88). «Los trescientos cuerpos de libros de la historia de Nuestra Señora» se convirtieron en coprotagonistas de esta aventura de Ocaña, compartiendo el escenario con las bestias de carga. Creo que la importancia de esta biblioteca, y del lector Ocaña, es una primera pista para lo que viene a continuación. No conocemos los títulos de los volúmenes que llevaba consigo, salvo uno, la Historia de Nuestra Señora de Guadalupe, de 1597, escrito por Gabriel de Talavera. Esto es, el mismo Talavera cuya milagrosa historia se convertiría en recurso clave para todo, desde las oraciones de Ocaña, pasando por sermones (los suyos y los de otros), hasta un drama en tres actos que compuso y pudo ver dos veces representado en Potosí y Chuquisaca. El mismo Talavera que había abrazado la comparación que hiciera

España. Está numerada erráticamente en varios lugares y comienza en un folio que lleva el número 2. Existen dos ediciones académicas recientes: Diego de Ocaña, Viaje por el Nuevo Mundo: de Guadalupe a Potosí, 1599-1605, eds. Blanca López de Mariscal y Abraham Madroñal Durán, con Alejandra Soria (2010) y Diego de Ocaña, Memoria viva de una tierra de olvido: Relación del viaje al Nuevo Mundo de 1599 a 1607, ed. Beatriz Carolina Peña (2013). Cuando cito o hago referencia al manuscrito de Ocaña en este ensayo, como arriba, proporciono el lugar en la numeración del archivo o bien refiero y a veces corrijo) la edición de López de Mariscal y Madroñal Durán (Ocaña 2010). Sobre estas ediciones y las modificaciones que realizan ver Mills (2016), y también la aguda lectura de la edición de 2010 de Arrizabalaga (2011). Para situar al autor y al manuscrito en su contexto ver Mills (2008). Para más información sobre los problemas del manuscrito (dimensiones, numeración, manos que intervienen en el manuscrito) puede verse la introducción de Peña a su edición de Ocaña (2013: 15-19). El reporte de la muerte de Ocaña: AMG, Códice 61, Necrología de monjes, 1600-1747, f. 7r. 
Escobar Cabeza de Vaca respecto de las fundaciones de santa Elena en Tierra Santa, una segunda pista.

Gabriel de Talavera no era, ni mucho menos, el único en haber absorbido las formas y el contenido de los relatos de peregrinaciones a Tierra Santa del Medioevo tardío y la temprana era moderna, en general, y del Luzero de la Santa Tierra de Cabeza de Vaca, en particular. Otro entusiasta debía de haber sido, seguramente, Diego de Ocaña, el demandador jerónimo que viajó por gran parte del Virreinato del Perú entre 1599 y 1606, y que elogiaba mucho su copia de la Historia de Talavera. Es más, me gustaría sugerir que, en relatos de peregrinaciones a Tierra Santa (como el Lužero), Ocaña debió de hallar la inspiración de una forma narrativa poderosa y adaptable para organizar y dar justa expresión al relato de su viaje sagrado, así como para edificar y a la vez entretener a sus lectores. Un poetaperegrino como Escobar Cabeza de Vaca dependía de la familiaridad que tenían sus lectores con los protagonistas, escenas e historias principales de la Biblia, para atizar su interés en su propia aventura, y con las descripciones de lugares de una tierra que ya era sagrada desde hacía mucho tiempo. Por su parte, Diego de Ocaña no podía sino depender, asimismo, de una base similar de conocimientos y anhelos espirituales para poder ser comprendido. Su propósito estaba vinculado - en la medida en que era su extensión- con el que tuvieran los autores de cualquiera de los relatos de peregrinación a Tierra Santa. Ocaña y sus pares necesitaban describir aquello que era notable, maravilloso y estaba proceso de ser tocado y favorecido por Dios, en el nuevo escenario de devoción religiosa que eran las Indias, una tierra aún en proceso de volverse santa.

Si bien Escobar Cabeza de Vaca escribió en verso libre, él y Ocaña compusieron una narración mayormente episódica, en retrospectiva, acerca de su viaje, sacando el mayor provecho del atractivo de la inmediatez y de la autoridad del punto de vista de la primera persona. Yo soy aquella «persona que anduvo con los pies», insiste el peregrino en su prólogo al lector; aquel que «vio 
con los ojos y tocó con sus manos, por la misericordia de Dios, los más lugares de el testamento viejo» (Escobar Cabeza de Vaca 1587: Prólogo al lector). Cada uno de ellos intercala síntesis breves a lo largo de un solo acto de memoria acerca de cómo y dónde aquel narrador participó de un viaje largo y difícil. Tanto el poeta-peregrino como el demandador permanecieron largo tiempo en centros urbanos -Alejandría, El Cairo, Jerusalén para el caso de Escobar Cabeza de Vaca, el peregrino; Lima, Potosí y Chuquisaca para el caso del demandador-, pero asimismo atravesaron grandes extensiones desérticas, reales y metafóricas a sus ojos. Si bien cada autor revela ser consciente de un itinerario más o menos predecible, pre-escrito para ellos por anteriores narradores itinerantes, no dejan de poner énfasis en los imprevisibles cambios de planes y en cómo pusieron sus respectivos destinos en manos de la voluntad divina. Si debemos creerle a Escobar Cabeza de Vaca, su estadía de dos meses en El Cairo fue resultado de haber escogido él no unirse a la primera caravana hacia Palestina que tuvo a su disposición (Escobar Cabeza de Vaca 1587: f. 31r; Lama de la Cruz 2015: 380, 383-384). Por su parte, luego de su primera estadía en Lima, Ocaña afirma que dejó de lado su plan original de marchar hacia el norte, al reino de Nueva Granada, y, en lugar de ello, se embarcó hacia el conflictivo reino de Chile (Ocaña 2010: f. 71r; 159).

Haciéndolo cada uno a su manera, ambos autores centran su atención en ciertas partes de sus respectivos viajes; mientras que algunos de los tramos más largos están narrados de una forma mecánica, como a la distancia, tal como ha mostrado Víctor de Lama en relación a Escobar Cabeza de Vaca (Lama de la Cruz 2015: 382). Es como si estos autores, habiendo decidido qué era lo que más importaba en sus viajes hasta un determinado punto, de alguna manera se hallasen como coaccionados a terminar sus relatos; literalmente, como si condujeran a sus respectivos yo narrativos, con piernas que ciertamente les eran ajenas, hasta el final. De igual manera, ninguno de estos autores se muestra reacio a la modificación, fabricación 
y plagio de ciertos detalles a partir de cosas oídas o de lo escrito por otros autores, tal como Beatriz Carolina Peña ha empezado a explorar para el caso de Ocaña (Peña 2016), un tema que merecería mayor atención en un estudio aparte.

Las limitaciones de espacio de este pequeño ensayo no nos permiten una exposición amplia de estas influencias, al menos no como el tema lo merece. Tomando en cuenta esta circunstancia, mediante el empleo de algunos ejemplos representativos, tomados de los itinerarios de Escobar Cabeza de Vaca y de Ocaña respectivamente, me centraré en elucidar este rasgo definitorio que se halla ejemplificado tanto en el texto del poeta-peregrino, como en el del demandador jerónimo: la interacción entre un fin devocional y un propósito informativo, la coexistencia de un relato piadoso y de un reportaje de aventuras, que aquí solo podremos comenzar a estudiar.

Víctor de Lama de la Cruz ha sostenido recientemente que «en todo el libro de viaje de peregrinación suele haber un equilibrio entre las noticias propias del viajero y los contenidos habituales en una guía de los Santos Lugares», con el Lužero de Escobar Cabeza de Vaca como ejemplo de ello (Lama de la Cruz 2015: 382). El ensayo de Lama de la Cruz es excelente, y la idea de un equilibrio entre las partes apropiadas y el relato de aventuras es atractiva, tanto en sentido retórico como imaginativo. No obstante, en mi lectura del Luzero, y haciendo una sugestiva yuxtaposición con la Relación de Ocaña, no ha sido posible separar «episodios de aventuras» de aquellos otros manifiestamente piadosos; y esta lectura me lleva, finalmente, a cuestionar la precisión del término equilibrio, con su implicación de balance y de un autor en dominio completo de su obra, capaz de sopesar sus excursos narrativos, ejecutar todos sus propósitos y aun de restringir todos sus posibles significados a los lectores de la obra. En los relatos compuestos por Escobar Cabeza de Vaca sobre Tierra Santa, y por Ocaña sobre las Indias, las ideas de balance y simetría - porque sus autores solo ejecutaron lo que se habían propuesto- conllevan el riesgo de alejarnos de lo que sería lo 
más vital de estos textos: cómo la aventura y el propósito devocional se entremezclan e interrelacionan, a cada momento, distrayendo al lector pío y pergeñando a la vez una aventura santa.

Comenzaremos con la descripción que hace Cabeza de Vaca de su piadosa visita al lugar «que los moros llaman Matarea», al norte de El Cairo (Escobar Cabeza de Vaca 1587: f. 28v-29r). El evangelista san Mateo había relatado la historia de la huida de la Sagrada Familia a Egipto, escapando de la persecución del rey Herodes (Mt. 2: 13-23), un relato que, en la medida de que se volvía con el paso de los siglos más y más apreciado, fue objeto de alteraciones, precisiones y amplificaciones, en las que se mezclaron opiniones populares y no pocos relatos de peregrinaciones. Inspirado por la lectura de las relaciones de sus predecesores y las aseveraciones de no pocos guías del lugar, en 1584 Cabeza de Vaca buscaba una vivienda y jardín específicos en los que la Sagrada Familia se habría refugiado. Este lugar se hallaba custodiado por un solemne moro que pidió limosna para dar acceso, informaba Cabeza de Vaca, reconociéndose a sí mismo en la tropa de viajeros devotos que se habían convertido en una fuente de dinero para los habitantes locales. ${ }^{13}$

Los peregrinos sabían de una vieja higuera -a veces referida por otros viajeros como la «higuera del faraón»- bajo la cual la misma María habría descansado, exhausta por la travesía a través del desierto. De acuerdo con nuestro autor, se decía que dos milagros protagonizados por la Virgen y el Niño habrían tenido lugar ante los ojos de José. Primero, en gratitud por poder acoger a la Reina del Cielo bajo sus ramas, el árbol había dado la bienvenida a la Virgen formando una concavidad como para servir de trono, dentro de la cual ella había podido descansar. Luego, se decía que Dios había proveído a la Sagrada Familia con agua, y al sagrado árbol con riego,

13 Respecto del número de visitantes a la casa en la que se supone que la Virgen María pasó los siete años d huida a Egipto, y la así llamada «huerta de bálsamo» en la que habría descansado, véase Víctor de Lama de la Cruz (2013). 
de una manera memorable. Tan pronto como María señaló a José que si solo hubiese agua en aquel lugar, ello les ahorraría el retornar a la ciudad, su Santo Hijo escarbando en la tierra hizo salir «una copiossa fuente / de agua celestial y cristalina». ${ }^{14}$

El fraile franciscano Antonio del Castillo, autor de un relato posterior, quizá el más popular en su género en España, de un viaje de peregrinación a Tierra Santa (1654), registró observaciones complementarias acerca de la higuera del jardín de Matarea, donde la Virgen y familia habrían residido durante dos meses. Del Castillo había leído, por supuesto, acerca de lo que iba a encontrar antes de adaptar información y trabajar a partir de ella; una de sus fuentes debió de haber sido el Lužero de Escobar Cabeza de Vaca. «Dizen muchos autores», escribió Del Castillo, que cuando se acercaron allí los soldados que envió el rey Herodes para capturar a la Sagrada Familia, la gran higuera abrió su tronco para albergar y así esconder a la Virgen, permitiéndoles escapar. Para Del Castillo, como para Escobar Cabeza de Vaca, y muchos otros antes de él, ver y tocar eran una clave casi inexpresable para creer, pues allí, ante cada uno de ellos, estuvo el mismo árbol acerca del cual se contaban tan milagrosas historias. «Oy día se muestra este árbol abierto en dos partes», entonaba Del Castillo, «y es tenido en gran veneración por los christianos». ${ }^{15}$

Escobar Cabeza de Vaca relataba que un sinnúmero de peregrinos y aun sultanes de religión musulmana habían llegado hasta la «casa preciosissima», que se suponía el mismo san José había edificado en aquel lugar, en busca no solo de aquellas historias sagradas, sino también del «bálsamo perfumado» que emitía y que era conocido por sus propiedades milagrosas (Escobar Cabeza de Vaca: 28v,

14 Escobar Cabeza de Vaca, Lužero, Canto IV, ff. 29r-29v.

15 Antonio de[l] Castillo, El devoto peregrino: Viaje de Santa Tierra (1654 en Jones 1998, f. 119, 413-462, cito p. 431). De acuerdo con Jones, hubo 13 ediciones del relato de Del Castillo entre el publicado en Madrid, en 1654, y el que se publicó en Tarragona, en 1759. 
30r). A pesar de que, para la época de Escobar Cabeza de Vaca, ya no existía aquel bálsamo, aún quedaban sus poderosos vestigios. El poeta-peregrino adaptó sus descripciones a su condición de estudioso de los relatos de sus predecesores, que había anticipado su propia experiencia física y espiritual.

«Ay en cierta pared de aquella casa / una concavidad como ventana, / algo pequeña, y fabricado en quadro, escribió, a donde dizen que la Virgen pura / ponia a repossar a su amado hijo, / y bien lo muestra aquel olor suabe / que de ella sale, y siente el que alli llega». No había «ni ningún otro olor que se le yguale / ni avrá quien juzgue ser alguno déstos», informa Escobar Cabeza de Vaca, así como que, «los qüentas y rosarios que allí roçan / perpetuamente quedan olorosos». ${ }^{16}$ Casi tres cuartos de siglo más tarde, en la ya mencionada relación de 1654, Antonio del Castillo especificaba que era, en realidad, una piedra sobre la cual se había sentado el Niño, y no una «concavidad» en la pared, y que, desde entonces, aquella producía una «gran fragancia». Pero su argumento principal hace eco al de su predecesor Escobar Cabeza de Vaca; Antonio del Castillo hace énfasis en el hecho de que el poder sagrado de aquel lugar aún persiste. Junto a aquella casa y su piedra fragante estaba la fuente de la Virgen que regaba el «jardín del bálsamo», al que la gente aún acudía (Castillo [1654; f. 119] en Jones, ed. 1998: 413). A final de su visita en 1584, luego de que Pedro de Escobar Cabeza de Vaca escuchara misa, se entregó a un día entero de contemplación en Matarea «por gozar de lugar tan misterioso», y «tan suave y oloroso» (Escobar Cabeza de Vaca 1587: f. 30v; Lama de la Cruz 2015: 384-385; n. 34). Mucho depende de que Escobar Cabeza de Vaca pudiera recordar las fragancias, revivir los sentimientos y medir sus pasos dentro del lugar sagrado para ofrecer un testimonio fidedigno a sus lectores.

16 Escobar Cabeza de Vaca, Luzero, Canto IV, ff. 30r-30v. 
A lo largo de un itinerario -mayormente ya preestablecidopor los Andes centrales y del sur, Diego de Ocaña buscaba avivar el interés y la devoción de los lectores españoles con pruebas de los favores de Dios. Dado su papel de mensajero autorizado de una imagen reconocida de la Virgen en tierras lejanas, no debe sorprender el que su recorrido incluya varios encuentros con manifestaciones sobrenaturales de María. En estos casos, Ocaña recorre la delgada línea existente entre maravillarse abiertamente ante estas sagradas imágenes y buscar una suerte de conciliación entre diversas Marías que no vendrían a ser sino «rivales» de la guadalupana, cuya devoción él debía defender y preservar. Ocaña podía hallar alivio y consejo en el tesoro de historias de Escobar Cabeza de Vaca, Ceverio de Vera y los demás peregrinos de Tierra Santa, con las que estaría familiarizado. Pues, tanto en los Santos Lugares, como en las Indias españolas, el viajero devoto, consagrado a su misión, se hallaba forzado a convivir con una realidad muy imperfecta o, en todo caso, a evitarla de alguna manera. Escapar del poderío islámico, así como del control ejercido por otras empresas cristianas y los sucesores de los cruzados - cada cual con cierto grado de poder respecto de lugares y vestigios sagrados- provocaba situaciones en las que el peregrino de Tierra Santa debía retirarse o encontrar soluciones creativas. Lo mismo valía para Ocaña quien, luego de darse cuenta de lo próspera e inexpugnable que se hallaba una imagen de la Virgen de Guadalupe en Pacasmayo bajo la custodia de la Orden de San Agustín, en el norte del Perú, se retiró del lugar y reorientó sus esfuerzos a establecer una reproducción autorizada de la imagen de Extremadura en la capital Lima, una imagen que Ocaña colocó en un altar y promovió, con la abierta esperanza de que su devoción superara la de aquella otra, más antigua y ajena a su control, de Pacasmayo (Ocaña 2010; Mills 2003). Salir al mundo como viajero podía revelar las muchas maravillas de Dios, pero también mostraba que el destino de la fe era desconcertantemente variado, y que no estaba bajo el control del peregrino. 
El relato de Diego de Ocaña de sus experiencias con Nuestra Señora de Copacabana, en las orillas del Lago Titicaca, no se demora en detalles de una dimensión olfativa como Escobar Cabeza de Vaca, sino en otros aspectos, pero igualmente nos muestra la influencia que tuvieron las relaciones de viajes de peregrinación a Tierra Santa y los diversos requisitos establecidos para escribir la relación de un lugar o una cosa sagrada en el contexto del Nuevo Mundo. En el caso de Nuestra Señora de Copacabana, resulta el informe sustentado de un cronista agustino, Alonso Ramos Gavilán, acerca de aquella imagen y su santuario (Ramos Gavilán 1988; Mills, Taylor y Lauderdale Graham (eds.) 2002: 167-172; MacCormack 1984; Salles Reese 1997). Y se trata de una historia de la que Diego de Ocaña, pese a su papel de pasajero visitante en aquellas tierras, pronto se hizo cargo. Aquella imagen de La Candelaria era famosa porque se decía que había sido resultado de la admiración que profesara su escultor indígena a una imagen de Nuestra Señora del Rosario en Potosí. La Virgen de Copacabana era un fenómeno religioso americano y, ya para inicios del siglo XVII, su fama alcanzaba una extensión mayor que la de la Virgen de Guadalupe de Pacasmayo. Al igual que cualquier peregrino contemporáneo de Tierra Santa, Ocaña expresa su consideración por la Virgen de Copacabana conforme a determinados esquemas referenciales que le eran familiares, en particular, la devoción a la María de Guadalupe de Extremadura. Procediendo así, Ocaña neutralizaba y naturalizaba la potencial amenaza de esta novedad mariana, cuyo origen presentaba a un escultor indígena y era defendido por el hagiógrafo agustino. Nuestra Señora de Copacabana se hacía inteligible y maravillosa a los ojos de sus probables lectores al ser presentada de una determinada manera. «Es una imagen muy parecida en todo a nuestra Señora de Guadalupe», insistía Ocaña, especialmente «en las facciones del rostro, y del mismo altor que nuestra imagen» (Ocaña 2010: f. 314v, 445). 
Así como Escobar Cabeza de Vaca caminaba por el jardín de Matarea arriba descrito o medía en pasos la tumba de Cristo o el ancho de la humilde vivienda de María, en Copacabana, Ocaña se volvió también un «matemático devoto», un investigador piadoso que se proponía establecer medidas con gran precisión. Lo hacía con el mismo aparente cuidado y devoción con el que llevaba las cuentas de la recolección y envío de limosnas para los peregrinos de su santuario en España. «Sacando yo una medida que traía conmigo de nuestra Señora de Guadalupe, la medí con la de esta imagen de Copacabana y no tuvo la una más que la otra, sino que vinieron iguales» (Ocaña 2010: f. 314v, 445). Ocaña sabe precisamente cuándo el representante del santuario mariano de España, que recolecta limosnas e inspecciona las prácticas devocionales, debía dar paso, en un espacio ajeno, a una figura de mirada más amplia: la de un investigador que profundiza en lo sagrado. Como tal, Ocaña es cuidadoso y precavido al relatar su visita a la imagen y el santuario de Nuestra Señora de Copacabana, acallando la potencial rivalidad en favor de una comparación fiel y en conformidad con un marco universalista, una técnica que, como hemos visto, se había perfeccionado en los relatos de viajes de peregrinación a Tierra Santa. Ocaña pretende que aun los agustinos, frailes guardianes de la imagen de la Virgen de Copacabana, compartían su entusiasmo: «Quedaron los frailes muy contentos de ver, escribe, que su imagen se parecía en todo a nuestra Señora de Guadalupe» (Ocaña 2010: f. 314v, 445).

No mucho después, a mediados de julio de 1603, Diego de Ocaña visitaba un pueblo en el que se decía que sus pobladores indígenas habían hallado «una cruz de madera muy grande, con tres clavos de cobre» (Ocaña 2010: f. 317v, 449), la así llamada Cruz de Carabuco, un visita obligada en su itinerario de maravillas. Una buena parte de la narración de Ocaña de esta visita gira alrededor del tema de la madera de la que estaba hecha esta Cruz -el tipo de madera, para ser precisos, una especie rara que es «tan pessada», 
según describe, y que no existe dentro de 200 leguas a ambos lados del Collao (Ocaña 2010: ff. 317v-318r, 449). La gran cruz no podía haber llegado allí, concluía, sin la voluntad de Dios o alguna clase de acción sobrenatural. Ocaña pareciera conocer los reparos de José de Acosta y su famoso escepticismo respecto de las presuntas noticias de la visita de un apóstol a las tierras americanas (Acosta 1952: 36; MacCormack 1988) -comúnmente se pensaba en san Bartolomé o santo Tomás- pero al mismo tiempo se muestra igualmente entusiasta de aquella idea, que surgió principalmente en las crónicas de los agustinos. Sin embargo, él afirma que se convenció debido a las informaciones de los pobladores locales. Dicen los indios que la cruz había sido llevada a aquellos parajes por «un hombre descalzo con barba y cabello largo y que les predicaba y que les puso en medio de la plaza aquella cruz» (Ocaña 2010: ff. 317v-318r, 449). Ocaña debía de comprender el inmenso valor que se le iba a dar a ese objeto en las Indias, al tratarse de una reliquia sagrada de Tierra Santa o las catacumbas de Roma, un objeto sagrado que había sido poseído alguna vez por un santo apóstol y a través del cual Dios obraba en la Tierra. Contó que «de la cual cruz yo llevo conmigo a España una raja pequeña, por los muchos milagros que Dios obra por ella» (Ocaña 2010: f. 317v, 449).

La visita de Ocaña a la Cruz de Carabuco es la de un peregrino haciendo un importante alto dentro de un itinerario por unas tierras que se estaban volviendo santas. Su interés en la madera de que estaba hecha aquella cruz recuerda, asimismo, de modo más directo, a los relatos de viajes de peregrinación en Tierra Santa, cuyos autores solían ponderar el divino origen y acariciaban mentalmente las especiales cualidades de la madera de la Vera Cruz. Para Escobar Cabeza de Vaca, la cruz en la que murió Cristo era un objeto que poseía inmensos y nemónicos poderes sagrados: visitándola, contemplando su sacra materia, el pensamiento vuela y -exclamaba este autor- «se vee muy claramente en los muchos mysterios que encerrava aquel 
rico y santissimo madero» (Escobar Cabeza de Vaca 1587: f. 78r; 75r-82r). Para Escobar en Tierra Santa con la Vera Cruz, y para Ocaña con la Cruz de Carabuco del Apóstol Bartolomé, se trata de un «sancto madero», un medio perfecto para que el peregrino pueda reflexionar y orar. La madera es metáfora para todo, desde la edificación y florecimiento de la Iglesia, pasando hasta la de tabla de salvación que se ofrecía a la náufraga humanidad como un atisbo de esperanza de la Vida Eterna: para todo el mundo de seres humanos, congregados en medio de un mar tormentoso por Dios (Escobar Cabeza de Vaca 1587: ff. 75r-82r).

A lo largo de sus distintas travesías, tanto Pedro de Escobar Cabeza de Vaca como Diego de Ocaña hicieron hincapié en lo inesperado de sus hallazgos. Más aún, como se ha señalado antes, partes significativas del trayecto parecen haberse haber surgido de oportunidades casuales. Escobar Cabeza de Vaca, por ejemplo, deja pasar su primera oportunidad de viajar junto con una gran caravana en dirección a Jerusalén. La elección de quedarse en El Cairo y sus alrededores trajo consigo muchas aventuras. Pudo tener la oportunidad de visitar las antiguas pirámides y aprender de la tradición oral local muchas cosas, una de las cuales está registrada en su quinto Canto.

Narrando en primera persona, e interpolando relatos tomados de informantes y de sus propias lecturas, Pedro de Escobar Cabeza de Vaca despliega su propio método de viaje y ofrece así un relato lleno de descubrimientos. Un día, no hacía mucho, «un viejo moro», habiéndose topado con una abertura en la tierra a unas ocho leguas de El Cairo, llamó a sus hijos a que la vieran. El primer pensamiento de aquel viejo, según nuestro peregrino, fue que debía de haber hallado algún tesoro, el cual aliviaría las necesidades de su familia. Lo que, en realidad, el viejo y sus hijos vieron fue una cueva profunda, dentro de la cual había: «un estraño espectáculo de muertos, / mujeres y hombres, todos arrimados / a las paredes de la cueva obscura: / tan enteros estaban estos cuerpos / con sus pellejos, sus cavellos, y uñas / como si uvieran muerto en aquel día. / Todos ellos estaban 
muy vendados / con unas tiras de un pintado lienço / sobre cierto vetum, que antes ponian / el qual de corrupción los preservava» (Escobar Cabeza de Vaca 1587: ff. 32r-32v).

Como sugiere esta información de Escobar Cabeza de Vaca respecto de las antiguas técnicas egipcias de embalsamiento, el relato de un descubrimiento funciona como un portal narrativo hacia otras curiosidades, antiguas y modernas. Según sugiriéramos, aquí surge una metodología, que consiste en una fusión de elementos. Las experiencias de primera mano del peregrino, frecuentemente transmitidas bajo la forma de audaz aventura, se mezclan con relatos de los informantes, así como con todo aquello que el autor ha leído y estudiado de antemano. Lo que aquel viejo y sus hijos vieron en aquel relato se combina con lo aprendido de otras fuentes, lo que, a su turno, se mezcla con lo que el viajero llega a ver. Finalmente, aquello experimentado o aprendido se convierte en la base para formular teorías y hacer especulaciones, en este caso, respecto de concepciones sobre la muerte y el más allá en tiempo de los grandes faraones. La precisión y la veracidad -que determinen lo que realmente Escobar Cabeza de Vaca vio o descifró- resultan ser decididamente menos importantes que la finalidad última de formular una narración entretenida, conducida por explosiones de propio protagonismo y experiencia inmediata.

Este peregrino español de fines del siglo XVI se maravillaba de «tantos millares de cuerpos muertos», preservados con tanto cuidado (Escobar Cabeza de Vaca 1587: f. 32v). Ser momificado y sepultado de manera apropiada y en aquella cavidad había sido algo de vital importancia para un antiguo pueblo que no creía que la muerte natural era el final de la vida, sugiere Escobar Cabeza de Vaca, citando a un «sabio Mágico», con quien afirma haber conversado. «Todos afirmavan, asegura más adelante, que qualquiera que en ella se enterrase / forçosamente al mundo volvería» (Escobar Cabeza de Vaca 1587: f. 33r). 
«Gentiles todos...», los antiguos egipcios veneraban «diferentes, y contrarios dioses». La devoción a sus ídolos, de acuerdo con Escobar Cabeza de Vaca explicaba su deseo de ser sepultados dentro de ellos. Los personajes acaudalados eran sepultados rodeados de oro, plata y bronce, otros con hierro y barro, y los más envueltos en sus lienzos (Escobar Cabeza de Vaca 1587: ff. 32r-32v). No era que sus reflexiones en torno a esta serie de momias se restringieran a sus significados para el lejano pasado. Pues había un presente del que el peregrino formaba parte. Las momias podían adquirirse y no de manera muy diferente a las astillas que se presumía que provenían de la Vera Cruz. De acuerdo con un informante de Escobar Cabeza de Vaca, el sultán de aquella tierra en la que se descubriera esa gran cueva de muertos había recompensado a la familia musulmana que la descubrió con una momia. En el relato de Escobar Cabeza de Vaca, aquel regalo es un atisbo de lo que, desde tiempo atrás, había sido un tráfico abierto de momias egipcias hacia Europa en los siglos XVI y XVII. «El Turco» había robado ídolos de oro e incontables tesoros de las tumbas de las pirámides, según nuestro poeta-peregrino. Y como Escobar Cabeza de Vaca reconoce, las momias egipcias eran vendidas «a muchos mercaderes que las llevan», escribe nuestro autor, «por infinitas partes de la tierra» (Escobar Cabeza de Vaca 1587: f. 33v; Lama de la Cruz 2015: 397).

Al igual que la Tierra Santa que experimentó y narró el peregrino Escobar Cabeza de Vaca, la América de Ocaña, que estaba en proceso de volverse una Tierra Santa, se hallaba rodeada de toda clase maravillas, casi como si Dios mismo hubiese perdido la cuenta de la abundancia de portentos y curiosidades. A lo largo de un largo tramo de episodios, el jerónimo desvela un territorio maravilloso, rico y variado en paisajes y recursos. Desde sus terribles desiertos y oscuridades hasta lo que parecen signos de esperanza, la América de Ocaña está definida, en parte, por esta clase curiosidades y, de manera más particular, por su peculiar lectura de estos signos. Al igual que el viajero de Tierra Santa Escobar Cabeza de Vaca, Ocaña com- 
prende y se apropia de tales cosas para incorporarlas a la cristiandad católica española. En 1599, cerca del pueblo y puerto indígena de Eten, en la costa norte del Perú, Diego de Ocaña visitaba un lugar junto al océano, renombrado por sus rocas resonantes (Ocaña 2010: ff. 41v-42r, 121-122).

Aquellas rocas asombraron al jerónimo y a sus compañeros, a quienes describe explorándolas como niños, arrojando piedras de distintos tamaños, buscando ángulos, tratando de provocar una mayor variedad de sonidos. Ocaña no terminaba de describir a las dos piedras más impresionantes sonando «como una grande y sonora campana cuando la tocan con otra piedras» (Ocaña 2010: f. 41v, 121-122); y se las imaginó en España, reconvertidas en su uso y asombrando a todos los oyentes. Empleando métodos que nos recuerdan al peregrino Escobar Cabeza de Vaca en otras tierras, Ocaña recurre nuevamente a fuentes nativas para ampliar el sentido del lugar en los lectores: «Según la tradición de los indios viejos», alguna vez se hicieron sacrificios de niños en honor del Sol en aquel sitio, lo que hacía que su imaginaria conversión en las sonoras campanas de una iglesia pareciera aún más adecuada. De hecho, habría sido mejor si las grandes piedras resonantes hubiesen sido retiradas de allí. Hubiesen constituido un obsequio, si bien pesado y estorboso, bastante curioso para el placer del mismo Rey de España, continuaba Ocaña, elucubrando en sus páginas cómo es que aquellas piedras se hubiesen podido transportar a lo largo de la costa y a través del istmo de Panamá, tal como se mueven «dos piezas de artillería» (Ocaña 2010: ff. 42r-42v, 122).

Ante dos grandes pirámides de los faraones de Egipto, Pedro Escobar Cabeza de Vaca se maravillaba de lo que él describía verdaderamente como una de las siete maravillas del mundo, «dos maquinas tan grandes / puestas en medio de un muy ancho campo (...) mil pies tienen de altura, estas Pirámides / y devajo de tierra van quinientos, / es cada qual quadrada, y de circuyto / tiene una milla» (Escobar Cabeza de Vaca 1587: f. 36r). Una de las treinta y un ilus- 
traciones en el manuscrito de Diego de Ocaña muestra el cerro rico de Potosí, con una admiración y precisión que recuerda y profundiza el sentido que tuvo para Escobar Cabeza de Vaca estar frente a las pirámides. Ocaña describe al cerro como la «octava maravilla del mundo, pues toda la montaña está hecha de plata» y, en otra parte, como una gran «máquina». De forma característica, Ocaña dialoga con su ilustración, describiendo todo, desde la circunferencia que forma la falda del cerro (11,033 yardas), pasando por la vida de los más de 100,000 indígenas agrupados en unas catorce parroquias, hasta las condiciones de trabajo de los 12,000 hombres andinos, quienes -según su descripción- iluminaban sus caminos con velas de sebo, subían por escaleras hechas de sogas y duelas desde peligrosas galerías, llevando el mineral, activando los molinos, llenando los sacos de plata en lomos de llama para su traslado desde la sierra hasta los barcos en la costa (Ocaña 2010: ff. 168v-169r, 256-257).

Es iluminador notar también que Ocaña empleaba los mismos métodos, mediciones y especulaciones en los relatos de sus visitas a los antiguos sitios andinos, especialmente el de Tiahuanaco (perteneciente al Horizonte Medio [alrededor de 500-1100 d.C.], a unas doce millas de la orilla sur del lago Titicaca, en lo que hoy es la parte occidental de Bolivia occidental), que él visitó a mediados de julio de 1603, junto con el cura del pueblo de indios de Tiahuanaco como guía. Ocaña escribe que anduvo en medio de dos fortificaciones de piedra tan grandes y bien pulidas que lo dejaron con una sensación de asombro (Ocaña 2010: f. 316r, 447). ${ }^{17}$ «Para poder escribir todo lo que aquí menciono, señala Ocaña, fui hasta esas construcciones junto con el cura, quien estuvo a mi lado para enseñármelo todo» (Ocaña 2010: ff. 316r-316v, 447). ${ }^{18}$ Para Ocaña, la combinación de

17 Relación, f. 316r; Viaje, 447: «dos fuertes de piedras tan grandes y tan pulidamente labradas».

18 Relación, ff. 316r-316v; Viaje, 447: «... que para poder escribir lo que aquí digo, fui a los edificios con el cura de aquel pueblo, que fue conmigo para enseñármelo todo». 
orden geométrico, un labrado impecable y el mismo tamaño de muchos de los bloques, junto con la aseveración, proveniente seguramente del sacerdote que lo acompañaba, de que no había otras piedras de aquella clase ni canteras cercanas, en cincuenta leguas a la redonda, es lo que más le sorprende. Tiahuanaco es un misterio, una más de las «cosas notables», una maravilla del pasado, que precisaba ser comentada (Ocaña 2010: f. 316r, 447). ${ }^{19}$ En otras palabras, se trataba de otro sitio en América que había que ver, donde había que entrar y tocar, y del que había algo que aprender; y de formas fascinantemente parecidas a como hacían sus indagaciones los peregrinos de los lugares sagrados (Escobar Cabeza de Vaca en El Cairo y alrededores), en el camino de las maravillas religiosas.

He defendido que es importante considerar las maneras en las que, como su principal grupo de interesados lectores en Guadalupe de Extremadura, Diego de Ocaña era un ávido lector, incluso más de lo que se ha señalado de este demandador en movimiento Ocaña recibió una profunda inspiración de varios tipos de textos, a menudo interpuestos, que enmarcaban pero también permitían entender lo que veía y relataba. Sugiero que nuestras indagaciones respecto a cómo Ocaña traía consigo varios repertorios de textos y vertía esa familiaridad e inspiración en su obra, muy especialmente incluyendo sus reelaboraciones del mismo material, se vuelven vitales para nuestra apreciación de su manuscrito así como para una comprensión más general del mismo.

Con la intempestiva muerte de su experimentado compañero Martín de Posada, tan cerca del inicio de aquel viaje, el infortunio sobrevino a Diego de Ocaña. Pero los aprietos se volvieron en una oportunidad que él pronto abrazó. Y así, lo que en las manos de cualquier otro podría haber sido meramente un útil reporte para sus

19 Relación, f. 316r; Viaje, 447: «en cinquenta leguas alrededor no hay piedras de aquel grano de aquéllas, ni hay cantera...». 
superiores jerónimos ${ }^{20}$ y para unos pocos funcionarios de Indias, pronto se convirtió en algo mucho mejor.

He indagado en la manera como Diego de Ocaña crea un convincente viaje sagrado y se presenta a sí mismo como un aventurero de lo sagrado. Una de las claves para entender los modos como Ocaña determina su itinerario, establece su selección de mirabilia y de episodios significativos, su atención al entorno así como a la edificación, incluso su manera de narrar su viaje en general, reside en la apreciación de varias clases de lecturas en especial su evidente inmersión en los relatos medievales y de la modernidad temprana

20 Por ejemplo, otros tres demandadores jerónimos que viajaron al Nuevo Mundo por encargo del monasterio de Guadalupe: Diego de Santa María, Diego del Losar, y Pedro de Puerto no fueron de ningún modo tan expansivos ni elaborados como Diego de Ocaña. Santa María, que viajó a la Nueva España en el último tercio del siglo XVI y, entre otras cosas, propuso la fundación de un monasterio jerónimo cerca de la ciudad de México en «una granja se llama Chapultepec» para alojar una imagen de la virgen de Guadalupe venerada en el valle central al menos desde 1562 e incluso antes. Se conservan dos de sus cartas: AGI, Audiencia de México, Leg. 69, Carta de Fray Diego de Santa María al rey, México, 12 de Diciembre de 1574 (citación desde f. 2r); Leg. 283: Carta de Fray Diego de Santa María al rey, México, 24 de Marzo de 1575. Sobre esta imagen de la virgen de Extremadura que parece haberse venerado en el Tepeyac al menos hacia el último cuarto del siglo XVI, ver Francisco de San Joseph (1743: 143-150). Ver también Lafaye (1976: 231-238). Diego del Losar (Ocaña supo de su viaje y se refiere a él como «de Losal»), también desde Guadalupe, viajó a lo largo del Perú antes de la visita de Ocaña. Pese a haber permanecido doce años en el terreno, parece haber dejado pocas noticias y además, se convertiría en un pugnaz recuerdo de lo que para su sucesor Ocaña significaba todo lo que no ayudaba a establecer su presencia y sus esfuerzos. Pedro del Puerto, desde el monasterio de San Jerónimo de Buenavista en Sevilla, es un ejemplo claro en este aspecto. Del Puerto viajó a todo lo largo del virreinato del Perú una década después de Ocaña, también recolectando limosnas por encargo de la Virgen y el monasterio de Guadalupe, y dejó apenas un seco y aburrido reporte de 32 folios de su viaje, fechado en 1624. Archivo del Real Monasterio de Guadalupe (AMG) Leg. 60, Relación del viaje que Fr. Pedro del Puerto profeso de San Jerónimo de Sevilla hizo a las Indias desde 1612 hasta 1623 para tratar asuntos del monasterio de Guadalupe. Fue transcrito y publicado (con algunos errores en la transcripción) con una introducción, por J. Francisco V. Silva (Puerto 1922-23). 
de viajes a Tierra Santa. El Luzero de la Santa Tierra de Pedro de Escobar Cabeza de Vaca (citado por Gabriel de Talavera, cuya Historia de la virgen y el santuario de Guadalupe (1597) era una obra destacada en la biblioteca de viaje de Ocaña), es parte de la pletórica colección de «viajes sagrados» en los que él se había embebido y llevaba grabados en su mente.

En este caso, como en muchos otros, Ocaña nunca se molestó en citar ni incluso en emplear literalmente los textos que le inspiraban. Su influencia en la imaginación y la escritura de Ocaña era más fundamental. En respuesta al desafío de crear su propia relación de un viaje a través de tierras y entre gentes todavía nuevas en la cristiandad católica, Ocaña necesitaba rendir tanto el significado como lo sagrado que había en los lugares en los que él había promovido o afianzado la devoción a nuestra Señora. Diego de Ocaña recordaba y ajustaba para sus propios propósitos claves desarrolladas en los relatos de peregrinaciones a Tierra Santa. Del mismo modo que esos viajes ofrecían una mezcla convincente de una presencia autorial, una descripción rigurosa, momentos de edificación espiritual, curiosidades y rarezas naturales, así como oportunidades para la invención y el entretenimiento, Diego de Ocaña reelabora y combina todas esas características asumiendo la figura de un lector que se convierte en aventurero de lo sagrado, y dispone sus propios viajes en una «fluida conversación» ${ }^{21}$ dentro de una tradición narrativa inspirada, una conversación con lectores del presente y del pasado, una conversación que surge a lo largo de vastas extensiones de tiempo y espacio.

21 Warner (2014: 44) hace una observación similar respecto de la forma con que se inspiran los cuentos de hadas. 


\section{REFERENCIAS}

Acosta, José de

1952 [1590] De Procuranda Indorum Salute. Edición de Francisco Mateos. Madrid: Ediciones España Misionera.

ANÓNIMO

1998 [ca. 1520] «Viaje de Tierra Santa» [Biblioteca Nacional de España, Ms. 10883]. En: Joseph R. Jones (ed.). Viajeros españoles a Tierra Santa, siglos XVI y XVII. Madrid: Miraguano Ediciones, pp. 107-243.

Arrizabalaga, Carlos

2011 «Reseña de Diego de Ocaña, Viaje por el Nuevo Mundo: De Guadalupe a Potosí, 1599-1605. Eds. Blanca López de Mariscal y Abraham Madrónal (2010)». Mercurio Peruano, n. 524 pp. 321-328.

BAKHTIN, Mikhail M.

1981 «Forms of Time and the Chronotope in the Novel (Notes Toward a Historical Poetics)». En: Michael Holquist (ed.). The Dialogic Imagination: Four Essays, trans. Caryl Emerson y Michael Holquist. Austin: University of Texas Press, pp. 84-258.

Barnes, Timothy

1981 Constantine and Eusebius. Cambridge: Harvard University Press.

Beaver, Adam G.

2013 «From Jerusalem to Toledo: Replica, Landscape and the Nation in Renaissance Iberia». Past \& Present, vol. 218, n. 1, pp. 55-90.

Bouza Álvarez, Fernando J.

2001 Corre manuscrito: una bistoria cultural del Siglo de Oro. Madrid: Marcial Pons.

Cardoso, Jorge

1652 Agiologio lusitano dos santos, e varoens illustres em Virtude do reino Portuga e suas Conquistas. 4 tomos (tomo 4 por Antonio Caetano de Sousa). Lisboa: Na officina Craesbeekiana. 
Ceverio de Vera, Juan

1964 [1596] Viaje de la Santa Tierra Que hizo Ioan Ceverio de Vera Presbitero y Acholito de la Sanctidad de Clemente VIII, desde la ciudad de Roma a la sancta de Hierusalem en el año de 1595. Con un itinerario para los peregrinos. Concepción Martínez Figueroa y Elías Serra Rafols (eds.). La Laguna: Instituto de Estudios Canarios.

Chevalier, Maxime

1976 Lectura y lectores en la España de los siglos XV I y XVII. Madrid: Turner.

Christian Jr., William A.

1981 Local Religion in Sixteenth-Century Spain. Princeton: Princeton University Press.

Constable, Giles

1988 Monks, Hermits and Crusaders in Medieval Europe. Londres: Variorum Reprints.

DieTz, Maribel

2005 Wandering Monks, Virgins, and Pilgrims: Ascetic Travel in the Mediterranean World, A.D. 300-800. University Park: Pennsylvania State University Press.

Escobar Cabeza de VAca, Pedro de

1587 Luzero de la tierra santa, y grandezas de Egipto, y monte Sinai agora nuevamente vistas, y escriptas por Pedro de Escobar Cabeza de Vaca de la Orden de Cavalleros Templarios de la Santa Cruz de Hierusalem. Valladolid: Casa de Bernardo de Santo Domingo.

Ecija, Diego de

1953 [ca. 1514] Libro de la invención de esta Santa Imagen de Guadalupe; y de la erección y fundación de este Monasterio; y de algunas cosa particulares y vidas de algunos religiosos de él Cáceres: Publicaciones del Departamento Provincial de Seminarios de F. E. T y de las J. O. N. S.

Eusebius [of Caesarea]

1890 Life of Constantine. Ernest Cushing Richardson (trans.). En: Nicene and Post-Nicene Fathers, Second Series, Vol. 1. Eds. Philip Schaff 
and Henry Wace. Buffalo, NY: Christian Literature Publishing Company.

Revised and edited for New Advent by Kevin Knight. <http:// www.newadvent.org/fathers/2502.htm>

1999 Life of Constantine. Traducción y edición por Averil, Cameron. Stuart Hall. Oxford: Clarendon Press.

GEARY, Patrick J.

1978 Furta sacra: thefts of relics in the central Middle Ages. Princeton: Princeton University Press.

Hunt, E. D.

1981 «The Traffic in Relics: Some Late Roman Evidence». En: Sergei Hackel (ed.). The Byzantine Saint: University of Birmingham Fourteenth Spring Symposium of Byzantine Studies. Londres: Fellowship of St. Alban and St. Sergius, pp. 171-180.

1982 Holy Land Pilgrimage in the Later Roman Empire Ad 312-460. Oxford: Clarendon Press.

2000 «The Itinerary of Egeria: Reliving the Bible in Fourth-Century Palestine». The Holy Land, Holy Lands, and Christian History a special issue of Studies in Church History 36). Woodbridge, Suffolk: Boydell \& Brewer, pp. 34-54.

HutCheon, Linda

1988 A Poetics of Post-Modernism: History, Theory, Fiction. New York: Routledge. <HTtPs://TSPACE.LIBRARY.UTORONTO.CA/BitSTREAM/1807/ 10252/1/TSPACE0167.PDF>

Jones, Joseph R. (ed.)

1998 Viajeros españoles a Tierra Santa (siglos XVI y XVII). Madrid: Miraguano.

KABATEK, Johannes

2007 «Las tradiciones discursivas entre conservación e innovación». Revista di Filología e Letterature Ispaniche, X, pp. 331-345. 
KABATEK, Johannes (ed.)

2008 Sintaxis histórica del español y cambio lingüistico: Nuevas perspectivas desde las Tradiciones Discursivas. Frankfurt; Madrid: Vervuert-Iberoamericana.

KLEIN, Holger A.

2010 «Sacred Things and Holy Bodies: Collecting Relics from Late Antiquity to the Early Renaissance». En Treasures of Heaven: Saints, Relics and Devotion in Medieval Europe. Martina Bagnoli, Holger A. Klein, C. Griffith Mann and James Robinson (eds.). New Haven: Yale University Press, pp. 55-67.

LAFAYE, Jacques

1976 Quetzalcóatl and Guadalupe: The Formation of Mexican National Consciousness, 1531-1813. Traducción de Benjamin Keen. Chicago: University of Chicago Press.

Lama de la Cruz, Víctor de

2015 «El Vallisoletano Pedro Escobar Cabeza de Vaca en su Luzero de la Tierra Sancta». Castilla: Estudios de la Literatura, 6, pp. 367-401.

Lasso de LA VEgA, Ángel

1882 «Viajeros españoles de la Edad Media». Boletín de la Sociedad Geográfica de Madrid, 12, pp. 227-257.

MacCormack, Sabine G.

1984 «From the Sun of the Incas to the Virgin of Copacabana». Representations, n. 8, pp. 30-60.

1988 «Pachacuti: Miracles, Punishments, and Last Judgment: Visionary Past and Prophetic Future in Early Colonial Peru». The American Historical Review, vol. 93, n. 4, pp. 960-1006.

Martinez Figueroa, Concepción y Elías Serra Rafols (eds.)

1964 «Introducción». En Juan Ceverio de Vera, Viaje de la Santa Tierra Que bizo Ioan Ceverio de Vera Presbitero y Acholito de la Sanctidad de Clemente VIII, desde la ciudad de Roma a la sancta de Hierusalem en el año 
de 1595. Con un itinerario para los peregrinos. Concepción Martínez Figuroa y Elías Serra Rafols (eds.). La Laguna: Instituto de Estudios Canarios.

Millares Carlo, Agustín

1932 Ensayo de una biobibliografía de escritores naturales de las Islas Canarias (siglos XVI, XVII, y XVIII). Madrid: Tipografía de Archivos.

MiLLs, Kenneth

2003 «Diego de Ocaña’s Hagiography of New and Renewed Devotion in Colonial Peru». En: Allan Greer and Jodi Bilinkoff (eds.). Colonial Saints: Discovering the Holy in the Americas, 1500-1800. Nueva York; Londres: Routledge, pp. 51-76.

2008 «Diego de Ocaña (ca. 1570-1608)». En: Joanne Pillsbury (ed.). Guide to Documentary Sources for Andean Studies, 1530-1900. Volumen 3. Norman, OK: University of Oklahoma, pp. 457-464.

2014 «Mission and Narrative in the Early Modern Spanish World: Diego de Ocaña's Desert in Passing». En: Andrea Sterk y Nina Caputo (eds.). Faithful Narratives: Historians, Religion, and the Challenge of Objectivity. Ithaca, N.Y.: Cornell University Press, pp. 115-131.

2016 «On the presentation of Diego de Ocaña, O. S. H. (ca. 1570 1608)». Colonial Latin American Review, vol. 25, n. 4, pp. 559-567.

MiLLs, Kenneth, William B. Taylor y Sandra Lauderdale Graham (eds.)

2002 Colonial Latin America: A Documentary History. Lanham, MD: Rowman \& Littlefield.

OCAÑA, Diego de

1599-1608 Relación del viaje de fray Diego de Ocaña por el Nuevo Mundo (15991605). Biblioteca de la Universidad de Oviedo (España), M-215.

2013 Memoria viva de una tierra de olvido: Relación de viaje al Nuevo Mundo de 1599 a 1607. Beatriz Carolina Peña (ed.). Barcelona: Paso de Barca y el Centro de Estudios y Cooperación para América Latina.

2010 Viaje por el Nuevo Mundo: De Guadalupe a Potosí, 1599-1605. Blanca López de Mariscal y Abraham Madrónal con la colaboración de Alejandra Soria (eds.). Madrid; Frankfurt; México: Iberoamericana-Verveurt; Bonilla Artigas Editores. 
OESTERREICHER, Wulf

2004 «Textos entre inmediatez y distancia comunicativas: El problema de lo hablado escrito en el siglo de oro». En: Rafael Cano Aguilar (ed.). Historia de la lengua española. Barcelona: Ariel, pp. 729-769.

PeÑA, Beatriz Carolina

2016 Fray Diego de Ocaña: olvido, mentira y memoria. Alicante: Universidad de Alicante.

Puerto, Pedro del

1922-1923 [1624] «Viaje de un monje gerónimo al virreinato del Perú en el siglo XVI». En: J. Francisco de Silva (ed.). Boletín de la Real Academia de la Historia, n. 81 (1922), pp. 433-60, y 82 (1923), pp. 132-164 y 201-214.

Ramos Gavilán, Alonso

1988 [1621] Historia del Santuario de Nuestra Señora de Copacabana. Lima: Edición de Ignacio Prado Pastor.

Ribadeneyra, Pedro de

1599-1601 Flos sanctorum o libro de las vidas de los santos escrito por el padre Pedro de Ribadeneyra. 2 tomos. Madrid: Luis Sanchez.

1604 Libro de vidas de santos, que comunmente llaman extravagantes, porque la santa Yglesia no reza dellos en el breviario Romano. Madrid: Luis Sanchez.

Rubio, Germán

1927 Historia de Nuestra Señora de Guadalupe; o sea: Apuntes históricos sobre el origen, desarrollo y vicisitudes del santuario y santa casa de Guadalupe. Barcelona: Industrias gráficas Thomás.

SALLES-REese, Verónica

1997 From Viracocha to the Virgin of Copacabana: representation of the sacred at Lake Titicaca. Austin: University of Texas Press.

SAN Joseph, Francisco de

1743 Historia universal de la primitiva y milagrosa imagen de Nuestra Señora de Guadalupe. Madrid: Antonio Marín. 
SigüENZA, José de

2000 [1595-1605] Historia de la Orden de San Jerónimo, ed. Franciso J. Campos y Fernández de Sevilla, 2 tomos. Salamanca: Junta de Castilla y León.

1793 Instrucción de maestros y escuela de novicios: arte de perfección religiosa y monástica, 2 vols. Madrid: en la oficina de Don Benito Cano.

Talavera, Gabriel de

1597 Historia de Nuestra Señora de Guadalupe consagrada a la soberana magestad de la Reyna de los Ángeles, milagrosa patrona de este sanctuario por Fray Gabriel de Talavera, prior de la misma casa. Toledo: Casa de Thomas de Guzman.

TANner, Norman P. (ed.)

1990 Decrees of the Ecumenical Councils. Londres; Washington: Sheed \& Ward; Georgetown University Press.

TAYLOR, William B.

2016 Theater of a Thousand Wonders: A History of Miraculous Images and Shrines in New Spain. Cambridge: Cambridge University Press.

Tena Tena, Pedro

1990 «Estudio de un desconocido relato de viaje a Tierra Santa». Cuadernos de Filología Hispánica, n. 9, pp. 187-203.

Vega, Pedro de la

1558 Flos sanctorum: la vida de nuestro senor Jesu Christo y de su sanctissima madre y de los otros santos segun la orden de sus fiestas. Revisado por Martín de Lillio. Alcalá de Henares: Juan Brocar.

Villegas y Selvago, Alonso de

1588 Flos sanctorum y historia general, de la vida y hechos de Jesu Christo, Dios y senor nuestro, y de todos los santos de que reza y haze fiesta la iglesia catholica conforme al brevario romano, reformado por decreto del sancto concilio Tridentino, junto con las vidas de los sanctos proprios de Espana, y de otros extravagantes. Madrid: Pedro Madrigal. 
1578 Flos sanctorum. Primera parte. Toledo: Diego de Ayala.

1580 Flos sanctorum nuevo y historia general de la vida y bechos de Jesu Christo y de todos los santos de que reza y haze fiesta la Iglesia Catholica. Zaragoza: Domingo de Protonariis.

WEBER, Elka

2005 Traveling Through Text: Method and Message in Late Medieval Pilgrimage Accounts. New York: Routledge.

WeIss, Gerhard

1988 «The Pilgrim as Tourist: Travels to the Holy Land as Reflected in the Published Accounts of German Pilgrims between 1450 and 1550». En: Marilyn J. Chiat y Kathryn (eds.). The Medieval Mediterranean: Cross-Cultural Contacts. St Cloud, MN: North Star Press of St Cloud, pp. 119-131.

WARNER, Marina

2014 Once Upon a Time: A Short History of Fairy Tale. Oxford: Oxford University Press.

Zamora, Hermenegildo

1976 Catálogo de libros de la antigua biblioteca del monasterio de Guadalupe. Zamora: Ediciones Monte Casino. 